\title{
Sinus Slowing With AV Block by ECG Finding
}

National Cancer Institute

\section{Source}

National Cancer Institute. Sinus Slowing With AV Block by ECG Finding. NCI Thesaurus.

Code C120617.

An electrocardiographic tracing demonstrating the simultaneous occurrence of a slowing sinus rate and $\mathrm{AV}$ block. 